\title{
Soil tillage related to other farm practices
}

\section{Introduction to the second day's subject}

\section{A. MOENS}

Soil tillage adds considerably to the costs of farm production. As such, the farmer should be intended to limit soil tillage to a minimum. He should select the cheapest possible techniques of soil tillage and substitute these by other less costly practices, as soon as these are available.

The opportunity to adopt new techniques of soil tillage and to substitute these by other practices like spraying is rapidly increasing due to an extensive development of farm tractors and farm machinery, respectively a rising flow of new and better chemical weed killers.

Besides the function of soil tillage as a cost element the situation has to be examined to what extent soil tillage contributes to the size and the quality of production on the farm - a subject dealt with extensively on the first day of this Conference.

From a management point of view the impact of soil tillage on production as well as on the level of costs of soil tillage practices are hard to define. This is undoubtedly a main cause why soil tillage compared to other activities on the farm is often bound to tradition and the picture of the future pattern seems not to be clear.

Like KUIPERs has pointed out previously soil tillage is even more complex than we would imagine if the direct cost - return relationship had been defined.

The subject for to day will show this complexity. It deals with the aspects of soil tillage that can lead to a reduction of other cost items like costs of sowing, harvesting etc.

Our attention will be focussed specially on situations where the total operating costs of the farm are reduced by the application of a special pattern of soil tillage practices.

The function of such practices can be listed under three main headings.

\section{1. a preparative function}

Soil tillage can make it possible to save materials like water, seeds and plant nutrients.

Examples: levelling of seedbeds, deep ploughing.

2. a substitutive function

Soil tillage can make it possible to introduce less-costing techniques like full mechanical harvesting and handling of potatoes on land where clod building has been avoided. 
3. a curative function

Faults made by previous operations that led to consolidation, puddling and smearing or dispersion of soil may be amended by a more extensive application of soil tillage.

In considering the three functions it is desirable to determine in each case what actually happens to the soil when tillage as well as other farm operations are carried out and what impact they have on management.

It is also extremely useful to know to what extent the design and the use of farm tractors and other farm machinery contribute to the objectives outlined previously.

I hope that the discussions on these topics during this part of the Conference will lead to a better knowledge. Especially to a proper answer to the following questions:

a. What is the impact of new farm techniques on the soil?

b. How can balance be achieved or maintained between soil tillage and such operations that damage valuable soil properties?

c. What information about soil treatment should be made available to engineering departments to improve the design and the efficient use of farm tractors and other farm equipment to meet future demands for profitable farming? 